\title{
Self-regulation strategies improve self-discipline in adolescents: benefits of mental contrasting and implementation intentions
}

\author{
Angela Lee Duckworth ${ }^{\mathrm{a} *}$, Heidi Grant ${ }^{\mathrm{b}}$, Benjamin Loew ${ }^{\mathrm{a}}$, Gabriele Oettingen ${ }^{\mathrm{a}, \mathrm{c}}$ and \\ Peter M. Gollwitzer ${ }^{\mathrm{a}, \mathrm{d}}$ \\ ${ }^{a}$ Department of Psychology, University of Pennsylvania, Philadelphia, PA, USA; \\ ${ }^{b}$ Department of Psychology, Lehigh University, Chandler-Ullmann Hall, Bethlehem, PA, USA; \\ ${ }^{c}$ Department of Psychology, University of Hamburg, Von-Melle-Park Hamburg, Germany; \\ ${ }^{d}$ Department of Psychology, University of Konstanz, Konstanz, Germany
}

\begin{abstract}
Adolescents struggle with setting and striving for goals that require sustained selfdiscipline. Research on adults indicates that goal commitment is enhanced by mental contrasting (MC), a strategy involving the cognitive elaboration of a desired future with relevant obstacles of present reality. Implementation intentions (II), which identify the action one will take when a goal-relevant opportunity arises, represent a strategy shown to increase goal attainment when commitment is high. This study tests the effect of mental contrasting combined with implementation intentions (MCII) on successful goal implementation in adolescents. Sixty-six 2nd-year high school students preparing to take a highstakes exam in the fall of their third year were randomly assigned to complete either a 30-minute written mental contrasting with implementation intentions intervention or a placebo control writing exercise. Students in the intervention condition completed more than $60 \%$ more practice questions than did students in the control condition. These findings point to the utility of directly teaching to adolescents mental contrasting with implementation intentions as a self-regulatory strategy of successful goal pursuit.
\end{abstract}

Keywords: goal setting; academic performance; intervention; adolescent; selfregulation

\section{Introduction}

Research on goal pursuit distinguishes between aspects of goal setting, such as goal choice and commitment, and aspects of goal striving, such as goal enactment and shielding (Lewin, Dembo, Festinger, \& Sears, 1944; see also Atkinson, 1957; Carver \& Scheier, 1999; Heckhausen \& Gollwitzer, 1987; Locke \& Latham, 1990; Oettingen \& Gollwitzer, 2001; Shah \& Kruglanski, 2002). Successful goal attainment requires sufficient commitment to goals during the goal-setting phase of goal pursuit (Oettingen, 1999), as well as effective planning and enactment of goal-oriented behaviours during the subsequent goal-striving phase (Gollwitzer, 1999).

Goal setting is not an altogether straightforward process, in part because individuals have multiple and sometimes conflicting wishes. Similarly, numerous

\footnotetext{
*Corresponding author. Email: duckworth@psych.upenn.edu
} 
problems can thwart taking effective action towards a desired goal during the goal-striving phase (e.g. missed opportunities to act, distractions, bad habits, the difficulty or unpleasantness of required action, etc.). Mental contrasting, the contrasting of fantasies about a desired future with reflections about obstacles that prevent their realisation, is a strategy that has been shown to potentiate goal commitment in adults (Oettingen, 2000; Oettingen, Pak, \& Schnetter, 2001). Supplementing a goal to which an individual feels committed with an implementation intention, a plan that details when, where and how the individual will take action, makes goal realisation more probable (Gollwitzer, 1999; Sheeran, Webb, \& Gollwitzer, 2005).

In the current investigation, we test an intervention that prompts both mental contrasting (to facilitate goal setting by strengthening goal commitment) and the subsequent formation of implementation intentions (to facilitate goal striving by effective planning) on 'real-world' adolescent self-regulation. Adolescents struggle with the pursuit of long-term goals (Romer, Duckworth, Sznitman, \& Park, 2010). Setting long-term goals and striving for their attainment require sustained self-regulation (Pintrich \& Zusho, 2002; Reyna \& Farley, 2006). Academic responsibilities, for instance, are recognised by most adolescents as important but are also effortful, tedious and sometimes frustrating. Indeed, even adolescents who do well in school report being neither happy nor intrinsically motivated while they study; rather, most adolescents study in order to achieve long-term goals, including getting good marks (Wong \& Csikszentmihalyi, 1991). Not surprisingly, therefore, self-discipline predicts academic achievement among adolescents, including performance on standardised tests, independently of IQ (Duckworth \& Seligman, 2005). The present study tests the possibility that adaptive self-regulatory strategies can be directly taught to adolescents with relatively enduring effects on goal-directed behaviour.

\section{Mental contrasting: a self-regulatory strategy for goal setting}

The model of fantasy realisation (Oettingen, 2000; Oettingen et al., 2001) delineates three different routes to goal commitment: indulging, dwelling and mental contrasting. Indulging entails fantasising about a positive future without considering obstacles of present reality that stand in the way of realising this desired future (Oettingen et al., 2001). Dwelling, another one-sided way of thinking, entails reflecting on negative aspects of the present reality without elaboration of the desired future. To the contrary, the strategy of mental contrasting entails conjoint mental elaboration of the desired future and the present reality, thereby making both simultaneously accessible and creating strong associations between them. In mental contrasting, the positive future is elaborated first, and the negative reality is framed as 'standing in the way' of realising the positive future. The simultaneous activation of the desired future and present reality emphasises the necessity for action. When expectations of success are high, mental contrasting energises individuals to take action and strengthens their goal commitment (Oettingen et al., 2009).

\section{Implementation intentions: a self-regulatory strategy for goal striving}

Goal commitment must be followed by effective goal striving in order for goals to be realised. Common challenges during the goal-striving stage include getting started and 
staying on track. Getting started involves recognising and seizing opportunities to act, as well as overcoming any reluctance to act (due to the unpleasantness of the act, for example). Staying on track involves protecting ongoing goal-directed activity from getting derailed. Gollwitzer (1999) suggested that making if-then plans (i.e. forming implementation intentions) would help individuals both get started and stay on track during the goal-striving stage.

Whereas mere goals (or goal intentions) have the format of 'I intend to achieve x!' whereby $\mathrm{x}$ specifies a desired outcome or behaviour, implementation intentions take the form of "And if situation y occurs, then I will perform the goal-directed behaviour z!' For example, an individual who has committed to the goal of losing five pounds may furnish this goal with an implementation intention, such as 'If I am dining at a restaurant and the waiter asks for my order, then I will ask for a salad.' In the presence of the critical situation, the intended goal-directed behaviour is initiated immediately (Gollwitzer \& Brandstätter, 1997), effortlessly (Brandstätter, Lengfelder, \& Gollwitzer, 2001) and without conscious intent (Bayer, Achtziger, Gollwitzer, \& Moskowitz, 2009).

People who furnish their goals with implementation intentions get started on their goals more reliably during inconvenient times such as holidays or busy days (Gollwitzer \& Brandstätter, 1997; Oettingen, Hönig, \& Gollwitzer, 2000, Studies 2 and 3), when goal-directed actions are unpleasant (e.g. performing regular breast examinations, Orbell, Hodgkins, \& Sheeran, 1997; cervical cancer screenings, Sheeran \& Orbell, 2000; resumption of functional activity after joint replacement surgery, Orbell \& Sheeran, 2000) and when goal-directed actions are easy to forget (e.g. regular intake of vitamin pills, Sheeran \& Orbell, 1999; signing of worksheets in a test battery, Chasteen, Park, \& Schwarz, 2001). Implementation intentions also protect ongoing goal-directed activity from getting derailed (i.e. staying on track). For instance, implementation intentions help individuals control intrusive thoughts and feelings (Gollwitzer \& Schaal, 1998), and they shield goal striving from detrimental self-states (e.g. ego-depletion; Webb \& Sheeran, 2003) and adverse situational influences (e.g. a loss-framed negotiation setting; Trötschel \& Gollwitzer, 2007).

\section{Combining mental contrasting with implementation intentions}

Although mental contrasting and implementation intentions are effective selfregulatory strategies when used independently of one another, in studies of adults, they are particularly effective when combined. For example, adult volunteers in a study on healthy lifestyle who completed training in mental contrasting with implementation intentions (MCII) were twice as physically active over the next four months than adults in an information-only group (Stadler, Oettingen, \& Gollwitzer, 2009). In this intervention study, participants in the MCII condition named their current most important wish regarding physical activity (e.g. biking to work), and mentally elaborated the most positive aspect they associated with realising this wish (e.g. getting into better shape). They then named and elaborated the most critical obstacle (e.g. feeling too tired in the morning). Thereafter, they formed three implementation intentions (e.g. If tomorrow morning I feel too tired to take the bike, then I'll grab my bike keys instead of my car keys!). A similar MCII intervention was used to help women to eat healthier (Stadler, Oettingen, \& Gollwitzer, 2010). Indeed, as compared to women who received nutritional counselling only, women in 
the MCII group increased fruit and vegetable consumption and sustained this increase over a period of two years; women who received only nutritional counselling returned to baseline levels of fruit and vegetable consumption over the same time period (Stadler et al., 2010).

To test whether mental contrasting with implementation intentions combined is more effective than either technique alone, Adriaanse et al. (in press, Study 2) randomly assigned college students wishing to reduce unhealthy snacking habits to three groups: mental contrasting (MC), implementation intentions (II) or both (MCII). Participants received a booklet with baseline questions about their snacking habits. In the MC condition, participants indicated the snacking habit they wanted to diminish most and identified the most positive aspect associated with successfully doing so ('What is it that would make it so good for you personally if you diminished your bad habit?'). They then identified the critical obstacle of present reality impeding this success ('What is the most important obstacle that stands in the way of diminishing your bad habit?'). In the II condition, participants chose an obstacle and then made a plan to overcome it ('Please make an if-then plan in which you link an obstacle to diminishing your bad habit to a response which will help you to overcome this obstacle when it occurs.'). In the MCII condition, participants first followed the $\mathrm{MC}$ prompt and then a version of the II prompt in which they used the obstacle they had just named in their if-then plan ('Now please make an if-then plan in which you link the obstacle you just named to a response which will help you overcome this obstacle when it occurs.'). As predicted, MCII was more effective at diminishing unhealthy snacking over the following week than either the MC or the II technique used alone.

\section{The effectiveness of mental contrasting with implementation intentions among adolescents}

The current study sought to determine the benefits of mental contrasting with implementation intentions for goal striving among university-bound high school students preparing to take the Preliminary SAT (PSAT) ${ }^{1}$ exam the following fall. The PSAT is a high-stakes standardised test taken by approximately 3.5 million American students each year to determine eligibility for merit-based scholarships and also to provide a predicted score for the SAT exam, used by most US universities in evaluating applicants. Preparation for the PSAT includes self-directed studying and practice-test taking throughout the summer, a generally unstructured and largely unsupervised time for adolescents. While prior studies have shown both mental contrasting and implementation intention strategies to increase goal attainment among adult participants, the current investigation examined possible benefits of integrating these strategies to help adolescents pursue endeavours that are vital for their development.

\section{Method \\ Participants}

Participants were 66 second-year students from a socio-economically and ethnically diverse urban state school in the Northeastern region of the USA. Admission to this high school is selective and based on evidence of prior academic achievement. Nearly all students attend two- or four-year colleges or universities upon graduation; 
therefore, general motivation to do well on the PSAT test is high. Approximately $12 \%$ of students at this school are from low-income families, as indicated by eligibility for federally subsidised free- or reduced-price lunch.

Students were randomly assigned and were blind to either an MCII intervention or placebo control condition. Of 107 students in their second year at this school, 91 provided written parent and child consent. On the day of the experiment, a field trip prevented 22 students from participating; the remaining 69 students were in class. Of the 37 students randomly assigned to the MCII group, two did not return their PSAT books at the conclusion of the study. Of the 32 students in the control group, one did not return the PSAT book at the conclusion of the study. These three students were excluded from all analyses. Students averaged 16.07 years of age $(\mathrm{SD}=0.33)$. Thirtyfive students were Caucasians, 23 were African-Americans, five were Asians, two were Latinos and one was Native American; $49 \%$ were females.

\section{Measures and procedure}

In May, students completed an assignment during English class to help them 'practice for the writing section of the PSAT'. The control and MCII writing packets were identical for the first few pages. To measure expectations of success and incentive valence, all students answered questions about the likelihood and importance of completing PSAT preparation workbooks that they knew would be given to them at the start of summer vacation. Specifically, to measure expectations of success, students answered 'How likely do you think it is that you will complete all 10 practice tests in the PSAT workbook?' using a seven-point Likert scale where $1=$ not at all likely and $7=$ very likely. To measure incentive valence, we asked 'How important is it to you to complete all 10 practice tests in the PSAT workbook?' using a seven-point Likert scale where $1=$ not at all important and $7=$ very important. All students then wrote down two positive outcomes they associated with completing all of the practice tests in the workbook (e.g. 'I would feel good about myself') and two obstacles of present reality (e.g. 'I'm too busy') that could interfere with this task.

On the final pages of the control packet, students wrote a short essay about an influential person or event in their life. In contrast, on the final pages of the MCII packet, students rewrote the first previously stated positive outcome associated with completing the practice questions, elaborated on this outcome in writing after imagining it 'as vividly as possible', and then did the same imagining and written elaboration for the first obstacle. The same steps were repeated for the second positive outcome and obstacle. Students then rewrote both obstacles and proposed a specific solution for each one. Specifically, they completed two if-then plans (i.e. implementation intentions) in the form: 'If [obstacle], then I will [solution].' Finally, students completed a third if-then implementation intention specifying where and when they intended to complete the workbook that summer.

In July, students were mailed Barron's 12th edition of How to prepare for the PSAT. These workbooks were collected in October immediately after students completed their PSAT. Two research assistants blind to condition counted the number of test questions completed in each book. In cases where coders disagreed, books were re-examined until a consensus was reached. ${ }^{2}$ Upon returning their book, students were asked whether or not they had taken a PSAT preparation course over the summer and were paid $\$ 10$. Demographic information and second-year final grades (to calculate grade point average [GPA]) were collected from school records. 


\section{Results}

\section{Students were successfully randomised}

As shown in Table 1, the MCII intervention group and placebo control group did not differ on stated incentive valence (importance) of workbook completion nor in expectations of success (perceived likelihood) of workbook completion. The validity of these two single-item measures of incentive valence and expectations of success was verified by their predictive association with the number of PSAT practice questions completed, $r=0.21, p=0.09$ and $r=.20, p=0.10$, respectively. Students assigned to the control group had slightly higher GPAs than did students in the MCII group, but this difference was not significant (Table 1). Similarly, chi-square tests revealed no significant group differences in gender, $\chi^{2}(1, N=66)=2.24, p=0.14$, phi $=0.18$ or race, $\chi^{2}(4, N=66)=7.95, p=0.10$, $p h i=0.35$.

\section{Workbook completion was higher in the intervention group}

About $16 \%$ of students in the MCII group and $34 \%$ of students in the control group participated in a summer PSAT preparation course, $\chi^{2}(1, N=66)=2.83, p=0.09$, phi $=0.21$. Several students reported that their summer PSAT course instructor encouraged them to complete practice questions in the workbook we had provided. There was also a trend towards girls doing more questions than boys, $t(64)=0.85, p=0.40$, $d=0.22$. We therefore controlled for gender and PSAT prep course participation in a simultaneous multiple regression model predicting completed practice questions from condition. As shown in Table 2, when controlling for prep course participation and gender, students in the intervention condition completed significantly more practice questions than did their counterparts in the control group, $\beta=0.27, p=0.04$. In this model, the average number of practice questions completed by students in the MCII intervention group was 140, whereas the average number of practice questions completed by students in the placebo control condition was about 84 .

Table 1. Summary statistics of MCII intervention and placebo control groups at baseline.

\begin{tabular}{|c|c|c|c|c|c|c|}
\hline \multirow[b]{2}{*}{ Variable } & \multicolumn{2}{|c|}{ MCII group } & \multicolumn{2}{|c|}{$\begin{array}{l}\text { Control } \\
\text { group }\end{array}$} & \multirow[b]{2}{*}{$\begin{array}{l}\text { Effect size } \\
\text { (Cohen's } d)\end{array}$} & \multirow[b]{2}{*}{$\begin{array}{c}\text { Group difference } \\
p \text {-value }\end{array}$} \\
\hline & $M$ & SD & $M$ & SD & & \\
\hline $\begin{array}{l}\text { Incentive valence of completing } \\
\text { practice questions }\end{array}$ & 4.68 & 1.62 & 4.46 & 1.74 & 0.13 & 0.60 \\
\hline $\begin{array}{l}\text { Expectations of completing } \\
\text { practice questions }\end{array}$ & 4.87 & 1.69 & 4.43 & 1.84 & 0.32 & 0.31 \\
\hline GPA & 87.97 & 5.79 & 89.75 & 4.26 & -0.35 & 0.17 \\
\hline
\end{tabular}

Table 2. Simultaneous multiple regression predicting completed PSAT practice questions.

\begin{tabular}{lcc}
\hline Variable & $\beta$ & $p$-Value \\
\hline Female & -0.16 & 0.19 \\
Participation in PSAT course & 0.29 & 0.02 \\
MCII condition & 0.27 & 0.04 \\
\hline
\end{tabular}

Note: $R^{2}=0.35, p<0.05$. 


\section{Discussion}

Students given the opportunity to use mental contrasting (to ensure goal commitment) with implementation intentions (to facilitate goal implementation) completed more than $60 \%$ more practice questions in preparation for an upcoming high-stakes standardised test than did students in a placebo control condition. These results suggest that mental contrasting with the subsequent formation of implementation intentions can be an effective self-regulation strategy for adolescents to master developmental tasks. The results are particularly impressive given the brevity of the intervention, the length of time elapsing between the intervention and task conclusion, and the many temptations posed to students during the particular time period of the intervention (summer vacation). In light of recent findings suggesting that a major reason for adolescents falling short of their intellectual potential is a lack of self-discipline (Duckworth \& Seligman, 2005; Duckworth, Tsukyama, \& May, in press), effective interventions geared at helping students exercise self-discipline are of pivotal importance.

There were several limitations of the current investigation, which we hope can be addressed in future research. First, we did not obtain measures of goal commitment before, during, or after the three-month period in which students were completing practice PSAT questions. Future studies should include a manipulation check to confirm the hypothesised mechanism of the mental contrasting component of the intervention (i.e. increased goal commitment). Second, because the intervention tested in this study combined mental contrasting with implementation intentions, the relative impact of each component on studying could not be assessed. Since implementation intentions are not effective in the absence of goal commitment (Sheeran et al., 2005), we expect that both components of the intervention contributed to its effectiveness. Moreover, prior research with adults has shown that the combined strategy of mental contrasting with implementation intentions is more effective than either component used alone (Adriaanse et al., in press). Future studies are needed using multiple intervention conditions to tease apart the independent and interactive effects of these strategies on behaviour in adolescents.

Finally, a question we did not address in the current study was the extent to which the skills of mental contrasting and forming implementation intentions generalised to other tasks beyond studying for the PSAT. To assess such transfer, future studies may teach students self-regulatory strategies in one domain (e.g. academic) and test their effects on behaviour change in other domains, such as physical exercise, healthy eating and prosocial interaction. We speculate that transfer effects of MCII may occur by at least two routes: first, people may learn the strategy well enough to apply it in another domain. Second, energisation triggered through mental contrasting may spill over into other domains.

The current investigation suggests that adolescents can learn self-regulatory strategies that substantially improve the achievement of valued academic goals. In particular, adolescents can be taught specific techniques for effective goal setting and goal striving. Our findings are consistent with prior experiments spanning various areas in the health domain showing that adults who learn these strategies show improved long-term goal attainment (Adriaanse et al., in press; Christiansen, Oettingen, Dahme, \& Klinger, 2010; Stadler et al., 2009, 2010).

The present study has important practical implications for instructional practice. Teachers might easily incorporate techniques such as mental contrasting with implementation intentions into existing curricula. For instance, when assigning valued and 
feasible long-term projects, teachers might ask students to mentally elaborate the benefits of completing the project as well as the obstacles that may hinder completion. Such mental contrasting should strengthen goal commitment and energise students to take action towards completing the project. Subsequently, a few additional minutes of classroom time might be devoted to formulate if-then plans specifying how students want to overcome or circumvent the obstacles to project completion. Such implementation intentions should help students get started and stay on track, obviating the obstacles they themselves identify as impeding the realisation of completing the project.

More generally, the present investigation suggests that adolescents can learn relatively simple self-regulation strategies that dramatically improve their ability to attain long-term academic goals. Teachers and schools may therefore consider whether their missions should extend to modelling and instructing students directly in optimal self-regulatory strategies, as well as offering structured opportunities to practice them. Much more work is needed, of course, to develop curricula around these aims. The potential benefits, particularly in terms of improving academic performance, recommend energetic efforts in this direction.

\section{Notes}

1. The PSAT is the Preliminary SAT, which was formerly known as the Scholastic Assessment Test.

2. Because the distribution of completed practice questions was skewed right for both the experimental and control groups, we used a square root transformation of practice questions to approximate a normal distribution. This transformed variable was used in statistical analyses but, for ease of interpretation, untransformed values were used to report means.

\section{References}

Adriaanse, M.A., Oettingen, G., Gollwitzer, P.M., Hennes, E.P., de Ridder, D.T.D., \& de Wit, J.B.F. (in press). When planning is not enough: Fighting unhealthy snacking habits by mental contrasting with implementation intentions (MCII). European Journal of Social Psychology.

Atkinson, J.W. (1957). Motivational determinants of risk-taking behavior. Psychological Review, 64(6), 359-372.

Bayer, U.C., Achtziger, A., Gollwitzer, P.M., \& Moskowitz, G. (2009). Responding to subliminal cues: Do if-then plans facilitate action preparation and initiation without conscious intent? Social Cognition, 27(2), 183-201.

Brandstätter, V., Lengfelder, A., \& Gollwitzer, P.M. (2001). Implementation intentions and efficient action initiation. Journal of Personality and Social Psychology, 81, 946-960.

Carver, C.S., \& Scheier, M.F. (1999). Themes and issues in the self-regulation of behavior. In R.S. Wyer (Ed.), Advances in social cognition (pp. 1-105). Mahwah, NJ: Erlbaum.

Chasteen, A.L., Park, D.C., \& Schwarz, N. (2001). Implementation intentions and facilitation of prospective memory. Psychological Science, 12(6), 457-461.

Christiansen, S., Oettingen, G., Dahme, B., \& Klinger, R. (2010). A short goal-pursuit intervention to improve physical capacity: A randomized clinical trial in chronic back pain patients. Pain, 149(3), 444-452.

Duckworth, A.L., \& Seligman, M.E.P. (2005). Self-discipline outdoes IQ in predicting academic performance in adolescents. Psychological Science, 16, 939-944.

Duckworth, A.L., Tsukayama, E., \& May, H. (in press). Establishing causality using longitudinal hierarchical linear modeling: An illustration predicting achievement from selfcontrol. Social Psychology and Personality Science.

Gollwitzer, P.M. (1999). Implementation intentions: Strong effects of simple plans. American Psychologist, 54, 493-503. 
Gollwitzer, P.M., \& Brandstätter, V. (1997). Implementation intentions and effective goal pursuit. Journal of Personality and Social Psychology, 73(1), 186-199.

Gollwitzer, P.M., \& Schaal, B. (1998). Metacognition in action: The importance of implementation intentions. Personality and Social Psychology Review, 2(2), 124-136.

Heckhausen, H., \& Gollwitzer, P.M. (1987). Thought contents and cognitive functioning in motivational versus volitional states of mind. Motivation and Emotion, 11(2), 101-120.

Lewin, K., Dembo, T., Festinger, L., \& Sears, P.S. (1944). Level of aspiration. In J. Hunt (Ed.), Personality and the behavior disorders (pp. 333-378). Oxford: Ronald Press.

Locke, E.A., \& Latham, G.P. (1990). A theory of goal setting and task performance. Englewood Cliffs, NJ: Prentice Hall.

Oettingen, G. (1999). Free fantasies about the future and the emergence of developmental goals. In J. Brandtstaedter \& R.M. Lerner (Eds.), Action and self-development: Theory and research through the life span (pp. 315-342). Thousand Oaks, CA: Sage.

Oettingen, G. (2000). Expectancy effects on behavior depend on self-regulatory thought. Social Cognition, 18, 101-129.

Oettingen, G., \& Gollwitzer, P.M. (2001). Goal setting and goal striving. In A. Tesser \& N. Schwarz (Eds.), Intraindividual processes: Volume 1 of the Blackwell handbook in social psychology (pp. 329-347). Oxford: Blackwell.

Oettingen, G., Hönig, G., \& Gollwitzer, P.M. (2000). Effective self-regulation of goal attainment. International Journal of Educational Research, 33, 705-732.

Oettingen, G., Mayer, D., Sevincer, A.T., Stephens, E.J., Pak, H., \& Hagenah, M. (2009). Mental contrasting and goal commitment: The mediating role of energization. Personality and Social Psychology Bulletin, 35, 608-622.

Oettingen, G., Pak, H., \& Schnetter, K. (2001). Self-regulation of goal setting: Turning free fantasies about the future into binding goals. Journal of Personality and Social Psychology, $80,736-753$.

Orbell, S., Hodgkins, S., \& Sheeran, P. (1997). Implementation intentions and the theory of planned behavior. Personality and Social Psychology Bulletin, 23, 945-954.

Orbell, S., \& Sheeran, P. (2000). Motivational and volitional processes in action initiation: A field study of the role of implementation intentions. Journal of Applied Social Psychology, 30, 780-797.

Pintrich, P.R., \& Zusho, A. (2002). The development of academic self-regulation: The role of cognitive and motivational factors. In A. Wigfield \& J.S. Eccles (Eds.), Development of achievement motivation: A volume in the Educational Psychology Series (pp. 249-284). San Diego, CA: Academic Press.

Reyna, V.F., \& Farley, F. (2006). Risk and rationality in adolescent decision making: Implications for theory, practice, and public policy. Psychological Science in the Public Interest, $7(1), 1-44$.

Romer, D., Duckworth, A.L., Sznitman, S., \& Park, S. (2010). Can adolescents learn selfcontrol? Delay of gratification in the development of control over risk taking. Prevention Science, 11(3), 319-330.

Shah, J.Y., \& Kruglanski, A.W. (2002). Priming against your will: How accessible alternatives affect goal pursuit. Journal of Experimental Social Psychology, 38(4), 368-383.

Sheeran, P., \& Orbell, S. (1999). Implementation intentions and repeated behavior: Augmenting the predictive validity of the theory of planned behavior. European Journal of Social Psychology, 29, 349-369.

Sheeran, P., \& Orbell, S. (2000). Using implementation intentions to increase attendance for cervical cancer screening. Health Psychology, 19, 283-289.

Sheeran, P., Webb, T.L., \& Gollwitzer, P.M. (2005). The interplay between goal intentions and implementation intentions. Personality and Social Psychology Bulletin, 31, 87-98.

Stadler, G., Oettingen, G., \& Gollwitzer, P.M. (2009). Physical activity in women: Effects of a self-regulation intervention. American Journal of Preventive Medicine, 36, 29-34.

Stadler, G., Oettingen, G., \& Gollwitzer, P.M. (2010). Intervention effects of information and self-regulation on eating fruits and vegetables over two years. Health Psychology, 29(3), 274-283.

Trötschel, R., \& Gollwitzer, P.M. (2007). Implementation intentions and the willful pursuit of prosocial goals in negotiations. Journal of Experimental Social Psychology, 43(4), 579-598. 
Webb, T.L., \& Sheeran, P. (2003). Can implementation intentions help to overcome egodepletion? Journal of Experimental Social Psychology, 39(3), 279-286.

Wong, M., \& Csikszentmihalyi, M. (1991). Motivation and academic achievement: The effects of personality traits and the duality of experience. Journal of Personality, 59(3), $539-574$. 